\title{
Analyzing Discourse of Saudi Speakers Using the Integrative Approach (Goffman, Gumperz \& Grice)
}

\author{
Thanaa Alhabuobi \\ Department of Languages \& Translation, Taibah University, Almadinah Almunawarrah, Kingdom of Saudi Arabia
}

\begin{abstract}
Approaches of discourse analysis, however, are at variance regarding their perspectives to discourse definition and its relationship with language and society. Based on such variance, each approach posits certain tools and applications consistent with its main principles. For instance, some approaches devote efforts to describing discourse itself and avoid accounting for underlying motivation and speakers' intentions such as "ISA" ${ }^{11}$ developed by Gumperz and Goffman, Schiffrin (1994). On the other hand, Grice's theory devotes concerns to both speaker's intention and hearer's interpretation and gives no or little attention to the effect of societal factor on linguistic stereotype, Haji-Hasan (2010). This paper is an attempt to use the integrative approach in discourse analysis. The integrative approach mainly presents critical results of a contrastive analysis by which the two approaches are mutually used to discourse analysis. Thus, this paper attempted to make use of the repertoire stemmed from the integrative approach to data analysis. The outcomes showed that socio-linguistic level taken from ISA and pragmatic level taken from conversational implicatures provided a very good tool to discourse analysis.
\end{abstract}

Index Terms - discourse analysis, interactional sociolinguistic approach, Gumperz, Goffman, Grice

\section{INTRODUCTION}

In recent years, there has been an increasing attention to discourse analysis by sociology, anthropology, and sociolinguistics; all work was dedicated to how people interact in social life. On the one hand, it is to study how people use language to express their identities, culture, and society. The perspective is to study the reflection and influence of socio-cultural background, ethnographical identity, and contextual presuppositions on the construction of language in interactional events. The main purpose of discourse analysis is to find out how people use language structurally and functionally in a social environment. In this sense, language is not only a linguistic phenomenon but social phenomenon as well.

Whether it is a monologue speech or interactional dialogue, language cannot be thought as an autonomous entity that works apart from social frame. Thus, discourse is necessarily discussed and analyzed within sociology, linguistics, and anthropology.

\section{PuRPose Of THE STUdY}

The main aim of this paper is to utilize Interactional Sociolinguistic Approach as a tool for analyzing discourse data. However, the current research paper also aimed at analyzing discourse from the perspective of the Integrative Approach developed by Haji-Hasan (2010) through which he proposes a newly methodological approach to discourse analysis. The integrative approach is a rich repertoire to discourse analysis since it pays a considerable attention to local vicinity posited by Grice's "analyzing interpretation and intention at specific context", and similar attention to global vicinity posited by Gumperz's "analyzing specific context within socio-cultural context".

\section{RESEARCH METHODOLOGY}

The current paper adopts analytical and descriptive research methodology. The analysis of data mainly depends on two approaches to discourse analysis: Interactional Sociolinguistic Approach and Grice's Theory to implicatures. For the purpose of the research, the researcher recorded a dialogue among three persons using face-to-face interaction, see Kasper (1999). The data is in the Arabic language; however, each portion taken for analysis was translated into English. After transcribing and reading the data carefully, certain segments of the data were selected for analysis and aspects of discourse were explored in depth. Review of literature to ISA was detailed whereas description of Gricean pragmatics was embedded in comparative analysis of the two approaches. The major base of analysis depended on the discourse strategy "speaking for another" stemmed from ISA at four levels: 1- alignments of chipping in and butting in, 2-

\footnotetext{
${ }^{1}$ ISA refers to Interactional Sociolinguistic Approach
} 
solidarity and micro-identity, 3- speaking for another and taking the role of the other, 4- types of wants and face threatening. The paradigm used in the analysis was to start with a neutral description of each example according to the unit of analysis mentioned above. The next step is to provide evidence to such description to validate the analysis and to pass final judgment. Doing so, the analysis attempted to examine and study all potentials related to discourse understanding to avoid as much deficiency as it could exist.

\section{REVIEW OF LITERATURE}

\section{A. Interactional Sociolinguistics Approach (ISA): The Principles}

First to be streamed is:

"This approach shares a great deal with the ethnography of communication framework from which it developed; But an interactional sociolinguistics approach pays particular attention to the clues people use to interpret conversational interaction within its ethnographic context" (Holmes, 2008, p. 372)

In her broad and underlying view to discourse, Schiffrin (1994) proposes this approach to analyze discourse. Several principles have been based as a ground from which specific strategies considerably used to discourse analysis. That is how to build an approximately comprehensive framework which includes contextualized cues with association to linguistic elements; specifically, the integration among 1- anthropology, 2- sociology, 3- language; including elements of linguistics, society, and culture. An important query to discourse analysis is how to found a base from which we could build language structures, and then function these units to release information about our identity, society, and culture. There is always a sort of emphasis on two broad concepts "interpretation" and "intention".

The two concepts imply that all parties involved in the situation where discourse takes place recognize the messages as they are intended. In order to achieve such goal, the researcher should bear in mind the followings:

A- Contextual Factors: cultural background, characteristics of the society, structure of the society "ethnicity \& nationalism", and social customs.

B- Current factors: mutual knowledge of the participants due to the event in which discourse takes place, face-toface correspondence, time, and place.

C- Participants' factors: identity, gender, psycholinguistic \& intellectual characteristics, cognitive level, background knowledge "presupposition", and social relationship.

D- Linguistic factors: syntactic-phonological features, lexicon and morphological levels, language characteristics, semantic vs. pragmatic use (relationship between structure and function), verbal vs. non-verbal cues, cohesioncoherence level, and metaphorical use.

The above factors are based on the work of (Levinson, 1983, p. 4-23), (Jorgensen \& Philips, 2002, p. 60-70), (Cutting, 2002, p. 2-5), (Johnstone, 2002, p. 3-5), (Schiffrin, 1994) (Holmes, 2008, p. 364-373).

In her explicit discussion to discourse analysis, Holmes (2008) identifies, based on Dell Hymes' framework, the main elements underlying the analysis of communicative events which seems very similar to the interactional sociolinguistics approach. These elements are as follows:

1- Identifying the type of the event: phone call, conversation, business meeting, lesson, and interview.

2- Identifying the topic and purposes of the conversation; for example, sport, politics, social interests, business plan.

3- The place where the event happens: home, class, public places, office.

4- Participants' characteristics and identities: age, gender, status, relationship among them.

5- Roles of the participants: speakers, hearers, audiences, bystanders.

6- Identifying the sequential speech acts: sequence and order of speech.

7- Identifying the contextualized cues: presuppositions, background knowledge, shared cultural background.

\section{B. Gumperz's Work}

To shed light on the current approach" interactional sociolinguistics approach", it is essential to scan Haji-Hasan (2010) and Auer \& Luzio (1992) contribution from a more explicit perspective to discourse analysis. The claim posited by his work depends on the principle of integrating "pragmatic" and "interactional sociolinguistics" in order to originate interpretive framework to discourse analysis. He maintains that depending on such framework would lead the analyst to the rationale beyond successful communication. Viewing Gumperz's work to this approach, he asserts that the participants resort to "co-occurrence" tools that involve linguistic patterns and non-linguistic patterns to convey interactional messages. More importantly, while presenting Gumperz's theory, Hajji-Hassan makes a critical account for the main distinction between Grice and Gumperz's theories to discourse analysis. Unlike Grice's theory whose main principle is to integrate between the speaker's intention and hearer's interpretation, Gumperz's theory focuses on the message interpretation within social frames. In other words, Gumperz concentrates on analyzing the message from the hearer's perspective; on the other hand, Grice accounts for analyzing factors of failure and factors of success to communication depending on the roles of both the speaker and the hearer.

According to "discourse strategies" stated by Gumperz, the participants in an interactional frame use different techniques to convey their message. In social interaction, the parties make us of all contextual cues available at all points of their serial conversation to pass communication deficiency. How to understand discourse strategy? An 
important query discussed by the author. The claim dedicated to this perspective indicates that the process of interpretation and production of messages are stemmed from the use of discourse strategies. In other words, people usually and subconsciously make use of contextualization cues. In this regard, Holmes (2008) identifies contextualization cues as a strategy to which language users resort to infer the "most likely interpretation of an utterance" (p. 373). Contextualization cues are linguistic and non-linguistic knowledge that play the basic role in message interpretation, termed as "pure indexicals" by (Eerdmans, Prevignano \& Thibault, 2003). It can be said that when speakers from different cultural background interact, the opportunity of misunderstanding increases which proves the significant role of contextualization cues. This means that the social homogeneity among people originates contextualization cues that could effectively support the conversational inference. Thus, distinction between Gumperz and Grice's can be summarized as:

Grice focuses on speaker's intention and hearer's interpretation "processed consciously"; within pragmatic principle, it focuses on local and narrow interpretation (Birner, 2013). Gumperz, on the other hand, focuses on the interpretation of the hearer "inferences" with regard to contextualization cues taking into account verbal and nonverbal signals "processed subconsciously". Hereby, Haji-Hassan (2010) posits the "Interactive Approach" to discourse through which he joins Grice and Gumperz's approaches and states its main principle:

"Therefore, by joining these two approaches together, the interactive approach focuses both on the speaker's meaning and the hearer's interpretation of the intended meanings." (p. 4)

It can be said, then, Gumperz seeks an interpretative sociolinguistic approach that presents a frame through which culture, use of language, meaning, and linguistic structure are influential factors to discourse analysis (Schiffrin, 1994). Most of Schiffrin's analysis to Gumperz's theory was dedicated to applying the principle of contextualization cues. She maintains that utilization of contextual cues which encompasses utilization of background knowledge "contextual presuppositions" is the way to mechanism of inferencing. Hypothetically, the speaker's intended meaning and the hearer's interpretation emanate from a package that includes several elements ranging from the broader scope "culturalanthropological structure of the society" to the narrower scope "language aspects, participants' characteristics, communication type (verbal, nonverbal, spoken, written, face-to-face interaction)".

\section{Goffman's Contribution}

Goffman adopts the same approach with its main concepts and implications stated by Gumperz. However, Goffman posits that understanding the form and meaning of the context figures out the contextualization cues from which the hearer could evaluate and inference the speaker's intentional meaning. It seems, then, Goffman's contribution is topdown and bottom- up; whereas, Gumperz's theory is top-down. Goffman gives distinctive characteristics to the participants involved in any interactional situation. His classification is based on the role each one plays in the event; the animator is the presenter of the talk, the author is the creator of the talk, the figure is described through the talk, and the principle is responsible for the talk. Thus, the concept of "identity" and "self" and "gender" are three important concepts in discourse analysis. This is one way to explain identity with "macro level social meaning "group, identity, status differences", (Schiffrin, 1994, p. 102).

\section{Speaking for Another as a Discourse Strategy}

The following lines of thoughts put "speaking for another" as a discourse strategy in a spot. Since discourse is organized and processed within a large number of mixed elements, the concept of interaction is an intricate process for analysis process though the parties of the conversation do their jobs automatically. Through interaction, participants manipulate talk in an unstable movement. In other words, at any point of the talk, the roles may change from; for instance, being a speaker to a hearer or vice versa. As indicated by Schiffrin (1994), "in an interactional conversation, mostly two roles are identified, language-user(s) who sends the message and language-user (s) who receives the message" (p. 102). Nevertheless, there is another role occupied by another participant who is often the "mediator" of the message; he mediates a specific point of talk between the sender and the recipient through interruption. In other words, the "mediator" or the spokesman- labeled as animator according to Goffman- is the presenter of the talk on behalf of another participant; explicitly to speak as a representative of other people. The referential code to this strategy is known as "situated meaning". This interactional strategy (speaking for another) or what is called turn-taking structure is basically performed through interruption when one's utterance is produced simultaneously with another one's. Interruption is distinctively classified into two main categories: 1- interruption most likely has negative connotation, 2overlap most likely has either neutral or positive meaning.

1-Adnangnments "chipping in" or "butting in"

Speaking for another can either be "polite interruption: chipping" or "rude interruption: butting in". Of course, this refers to the nature of relationship among participants and the meaning as situated in context. In other words, interruption has two different roles depending on situation; referring either to deferential or demeaning situated meaning the interrupter has to the speaker. Factors that help in distinguishing between the two types are 1- social relationship between the participants, 2- social identities, 3- speech act, 4- speech event, Schiffrin (1994).

\section{DATa ANALysis}




\section{Example 1}

a. Mohamad: University instruction is optional.

b. Noor: No, it is not, three-quarters of the courses you study is compulsory.

c. Mohamad: Excuse me?

d. Noor: Three-quarters of the courses you study $\downarrow^{\text {INT } 2}$

e. Adnan: We are Arabs.

f. Noor: compulsory, and if you go back to the plan, it is stated that you must finish 136 hours.

Before approaching the analysis, it is essential to highlight some information about the context of this example because interactional sociolinguistic approach to which discourse is analyzed necessitates such information. As mentioned in the previous assignment this conversation includes three participants: Noor, Mohamad, and Adnan. The participants belong to the same cultural background and well-educated.

First, the topic of the conversation is convenient to all participants in the sense that all of them have had at least reasonable knowledge concerning the universities curriculum. Mohamad is under-graduate; fourth level, Adnan is a graduate; BA degree, Noor is a lecturer. So, they are sharing common background knowledge to this particular issue. More importantly, all participants belong to the same society in the sense that their cultural background is identical with regard to social customs, ethnicity, and nationalism. The conversation is of an interactional event, face-to-face correspondence.

The participants at this point of discourse are discussing the educational system in Saudi universities in general and syllabuses in particular. In this example, we will analyze (1-e) "We are Arabs" to describe "speaking for another" as one strategy to discourse analysis. On the one hand, the speaker in (1-b) violates the maxim of manner according to Grice's theory in the sense that she uses an ambiguous lexical item "compulsory" by code-switching. In other words, all participants speak Arabic, at one point of her utterance in (1-b), the speaker inserts an English word that is (compulsory) in:

$$
\text { compulsory 3/4 لا مو اختباري انت المواد اللي تدرسها }
$$

According to Grice, the focus is on both speaker's intentional meaning and hearer's interpretation. On the other hand, considering the sequences of utterances, we claim that the hearer fails to interpret what is meant by "compulsory". The response of the hearer in (1-c) "excuse me?" gives a clear evidence of misunderstanding; the non-verbal contextualization cue "using final rising intonation in this case" refers to the use of some linguistic features to show uncertainty. For example, if $\mathrm{S}$ asks $\mathrm{H}$ to bring him something with unclear voice, mostly the expression "excuse me?" is used by $\mathrm{H}$ to implicitly express that he does not get the message. The explicit response could be "I am sorry I couldn't hear you clearly" or "excuse me I didn't hear well; would you mind repeating your question". There are two more evidence prove that the hearer does not interpret the utterance (1-b); 1- the repetition in (1-d) and 2- the utterance (1-e). First, the repetition of the same utterance by the same speaker in (1-d) right after the hearer's response in (1-c) proves that the speaker, who turns to be a hearer, interprets (1-c) "excuse me" according to contextualization cues posited by Gumperz who focuses on the message interpretation within social frames. As mentioned above, contextualization cues according to interactional sociolinguistic approach are linguistic and non-linguistic knowledge that play the basic role in message interpretation. The same cultural background with regard to language use in social interaction increases the opportunity of interpretation between $\mathrm{S}$ and $\mathrm{H}$; in other words, both of them know that one of the functions of "excuse $m e$ " is to express misunderstanding in a polite way. In regard to signals of contextualization cues, saying "excuse me" along with raised intonation is part of social practice used among people in Saudi. That is why ISA pays more attention to the clues people use to understand the social interaction and makes use of cultural background to interpret language function. In our case, because $\mathrm{H}$ considers the presupposition behind the use of such expression, she can interpret S's intentional meaning in "excuse me". In turn, $\mathrm{S}$ uses such clue depending on his own presupposition that he and the hearer share the same interpretation of the use of such signal.

There is, however, argument to ISA in regard to its focus on hearer's interpretation. First, the approach itself entitled as interactional approach, so the interaction necessarily means to fulfill the idea of "exchange messages" otherwise it cannot be said interaction. This means the communication event has two sides $\mathrm{S}$ and $\mathrm{H}$ who interchange roles. Second, if we focus on hearer's interpretation, the question is that: interpreting what? Simply there cannot be vacuum from which interpretation is gained. So, it is beyond dispute that $\mathrm{H}$ is to interpret what $\mathrm{S}$ says, and "saying" per se has nothing to do with interaction because we should look beyond semantic level; that is pragmatic level, (Thomas, 1995). One could not say that he understands what is said unless he understands what is intended; otherwise, no successful communication takes place. In this regard, understanding refers not to saying as an action; rather refers to what is meant by what is said. Therefore, we move in stages, from describing speech acts "Austen \& Searle's" to interpreting intentional meaning behind such act "Grice's" within the social context "Gumperz \& Goffman's". In sum, any analyst cannot ignore speaker's intention when approaching discourse analysis; therefore, it can safely be posited that the integrative approach posited by Hajji-Hasan (2010) is more efficient for such task than ISA. Without using the

$2 \downarrow^{\text {INT refers to the point of interruption }}$ 
integrative approach, my analysis will certainly have shortfall. How could I analyze "excuse me" for instance without considering hearer's interpretation, speaker's intention, and contextual clues?

We come now to analyze (1-e) "we are Arabs" from two perspectives; evidence stemmed from Grice's theory of conversational implicatures, and evidence of "speak for another" as a discourse strategy stemmed from ISA established by Gumperz and developed by Goffman. Consistent with Grice's theory, Altieri (1981); Holmes (2008) \& Haji-Hasan (2010), S of utterance (1-b), as just proved, has not observed the maxim of manner by using ambiguous lexical unit; that is "compulsory" in English instead of Arabic. Such utterance is met by the response in (1-c) which shows that $\mathrm{H}$ does not interpret the utterance by saying "excuse me". At this point of discourse, the roles of participants are Noor and Mohamad are exchanging speech; each one once being "author" of the talk and once being "recipient" of the talk, whereas Adnan is a bystander. At this point of discourse, interruption as a strategic tool to manage social interaction takes part. The bystander interrupts the conversation by saying "we are Arabs" in (1-e). From the cooperative principle point of view of Grice's theory, the response of the hearer in (1-e) shows that he infers the intended meaning of S of (1c). Although "excuse me" has no literal reference to misunderstanding, the $\mathrm{H}$ could interpret the non-literal meaning (intentional). By saying "we are Arabs" is a vivid indication that the S of "Excuse me" wants to say for instance "I am sorry I didn't understand what you meant by compulsory". This also supports the previous claim in which we posited that the speaker "Noor" interprets the intended meaning of the hearer so that she repeated her utterance "Three-quarters of the courses you study". On the one hand, we may say that although utterance (1-d) implicitly shows that the speaker recognizes that the hearer has faced difficulty understanding the point, but it seems she couldn't infer the exact point of misunderstanding so she only resorts to repetition. On the other hand, example (1-e) indicates that the speaker activates the intended meaning of "excuse me" in the sense that he interprets that the hearer (Mohamad) could not understand the English word "compulsory"; therefore, he says, "we are Arabs". Utterance (1-e) is a very impressive example of Grice's theory in its practical phase. The speaker of "we are Arabs" seemingly resorts to breaching all maxims: quality, quantity, relevance, and manner. Even though the hearer could infer the meaning, and her response in (1-f) evidence this claim. More explicitly, in her utterance (1-f) "compulsory, and if you go back to the plan, it is stated that you have to finish 136 hours", the speaker switches the word "compulsory" over to the Arabic language to maintain linguistic understanding.

Returning to discuss the same example "we are Arabs" from the other perspective, according to ISA. As mentioned above "speaking for another" can be thought as a discourse strategy. Before digging a solid ground to analysis, it is essential to mention this strategy with another perspective. When interruption takes part in a frame of "speaking for another", it means that there is responsibility for such interruption. In other words, is the responsibility for taking someone's part in speech given or taken? Of course, this depends on the relationship between the participants, identities, social status, the topic, and the social nature of the event. It can be thought of a rude way one uses against another in participation; for example, $\mathrm{S}$ takes H's part interruptedly to maintain an idea, change the subject, correcting the same idea, or deliberately trying to impose the idea that $\mathrm{H}$ is unable to fulfill appropriately, so he (S) is more suitable to accomplish the idea of speech. Also, it could be that the speaker wants to enforce a subject on the hearer himself as Schiffrin (1994:109) exemplifies "one is so invasive of another that she is unable to allow her to maintain her own position in conversation (cf. you are always putting words in my mouth)". In this case, responsibility is taken forcefully not given, and interruption could be considered demeaning. In contrast, let's think of a situation when one person is previously given the responsibility to speak for another. For example, a manager usually gives the responsibility to his secretary to reply phone calls, and of course the latter can talk on behalf of his manager whether for instance he can accept the call, receive a visitor, or do nothing of all. In this way, speaking for another, without disputation, is given and even if there is a sort of interruption, it will be characterized positive and polite. Given the two types of respon sibility, it could be said that there are factors governing the condition summarized as

1- Whether or not the person who takes the responsibility offers to do the act.

2- Whether or not the person asks someone else to do the act.

3- Whether or not the interrupter has the right to the act.

4- The status of the two persons.

Based on the above (factors affecting responsibility and factors determining the sort of interruption), we may say that "speaking for another" changes over the conversation. Back to our example "we are Arabs"; we can claim that the participant takes part interruptedly to speak on behalf of another participant. By saying "we are Arabs", Adnan takes the responsibility and attempts to identify the problem that Mohamad is facing. He wants to say that "being Arabs, we can't understand English, sometimes at least". More explicitly, the speaker at this point is trying to draw his mother's attention to the English word she uses and indirectly he is asking for more explanation. In addition, he wants to transfer the meaning that his cousin does not understand what the word "compulsory" means. Now, does the speaker in (1-e) take the responsibility and speak on behalf of his cousin forcefully? In other words, is the speech act positive or negative? In order to answer the question, we should consider the 1-social relationship between the two participants, their 2-social status in general "social identities", and their 3-status in this conversation; variables posited by Schiffrin (1994); Fairclough (2003) \& Holmes (2008) in ethnography of speaking. Given the relationship between them, the two participants are cousins and having a very good relationship, their ages are almost close to each other, and they were brought up in the same family. They share a lot of things and always show respect when speaking to each other. No 
restrictions or distance occurring between them. Interestingly, both of them know English and approximately their levels are same. Given their social status, both of them are of the same position; no one is higher or superior to the other; for example, father-son relationship or teacher-student relationship. Likewise, there is no great distinction between them via education and career. On the other hand, the role they have in the current talk "participation framework; status in this conversation" does not necessitate one be in superior position so that he has the upper hand to take the turn forcefully. Why? Because the current talk itself reflects sort of social interaction within friendly discussion rather than imposing one's idea using forceful authority.

The following lines of thoughts discuss another important issue regarding the "responsibility of speaking for another" through which "interruption" is activated. Let's start with this argument "whether or not the person who takes the responsibility offers to do the act". Apparently, there is no linguistic evidence for that; in other words, according to the locutionary level "Austin's theory" the speaker "Adnan" in "we are Arabs" does not explicitly offer to take the responsibility and speak for the other participant "Mohamad". For instance, Adnan didn't say "may I say something on your behalf to explain what you meant by: excuse me?" The second argument is "whether or not a person asks someone else to do the act". Likewise, the participant "Mohamad" does not ask Adnan explicitly to do the act; there is no question at level of linguistic unit. The third argument is "Whether or not the interrupter has the right to the act". The latter argument will be illustrated under the discussion of the two previous ones. We could say that the responsibility of "speaking for another" is taken and given implicitly not explicitly. Given the discussion about the relationship between the participants; social, status, identities, and all arguments presented in the above lines, we could claim that although there is no explicit offer, nor is there explicit question; the speaker "Adnan" takes the responsibility and does the act on behalf of "Mohamad". Consequently, the speaker has an embedding right to do the act and this right has a connotative sense within his social relationship with the other participant.

In sum, we may safely end up this part of discussion by what was early hypothesized; that is the "interruption" embedded at this point of talk is a discourse strategy used to "speak for another". Secondly, we have underpinned the assumption that "turn-taking" is acted by the speaker politely, having positive sense "chipping in" via the social relationship between the two participants, social status, participation framework, and their social identities. Contextualization cues also support our result, prosody and language rhythm used in the interaction; more specifically, at the current point of talk under discussion. Responsibility of turn-taking and "responsibility of speaking for another" through "interruption" is given and taken implicitly. However, there are other potentials in this regard:

1- Adnan takes the turn to speak for Mohamad because he depends on contextualization cues signaled by Mohamad in the sense that the latter does not know the word. In this case he is an animator of the talk.

2- Adnan takes the turn to speak for Mohamad to serve "self" and "other" in the sense that he also does not know the word and he wants to know. In this case, Adnan is both animator and author of the talk.

3- Adnan takes the turn to speak because he does not know the word and he wants to know the word and has no knowledge whether Mohamad knows or does know the word. In this case, we cannot assume that Adnan speaks for another, and he is only introducing himself and plays the role of the author and principle of the talk.

\section{2- Solidarity and micro- identity}

Supporting the previous argument, let's consider the role of "solidarity" as a level of "speak for another" in situated meaning. We will return to the same example:

a. Mohamad: University instruction is optional.

b. Noor: No, it is not, three-quarters of the courses you study is compulsory.

c. Mohamad: Excuse me?

d. Noor: Three-quarters of the courses you study $\downarrow^{\text {INT** }}$

e. Adnan: We are Arabs.

f. Noor: compulsory, and if you go back to the plan, it is stated that you have to finish 136 hours.

Before proceeding our discussion, let us highlight how "speak for another" reflects the identities and solidarity of the participants. Let's put it in a more solid ground by presenting personal information about the three participants. Both Adnan and Mohamad are males so first they share the same gender. In addition, their levels of education are approximately the same. More importantly, they are very close to each other due to their level of the English language proficiency. On the other hand, the third participant is a female; she is higher than them regarding the level of education and, particularly, the level of language proficiency. On the one hand, the variant level between the two males and the female reveals a sort of interactional disruption; I want to say that the ambiguity of the word "compulsory" seems like "threat" to communication from the perspective of Adnan and most likely to Mohamad. On the other hand, to maintain solidarity in the sense that both of them are equal in language interpretation, both of them are Arabs, and both of them fail to elicit the word meaning, Adnan resorts to strategy of interruption, and he takes the turn of speech in order to minimize "threats". The speaker in "we are Arabs" wants to state fidelity and solidarity with his peer "Salam" by using the linguistic unit "we" referring to "self" and "other". The "plural" pronoun "we" is indicating the role of linguistic structure in situated meaning. The two examples "excuse me" and "we are Arabs" reveals two important concepts. One: the speakers (Mohamad and Adnan) are trying to besiege and control the conversation by not allowing the other participant continuing her talk while both of them have difficulty understanding her speech. This can be clearly figured out in (1-f) when the speaker translates the word from English into Arabic "she could infer the meaning of 1-e" 
depending on contextualization cues "contextualization cues thus allow participants to infer the most likely interpretation", (Holmes, 2008, p. 373). We can also say that this utterance (1-f) is one of constitutes of Austin's model to speech acts "perlocutionary act", the force or effect the speaker makes on the hearer.

Significant here is that the speaker in example (1-e) violates all maxims of Grice's theory; his utterance has no relevance to the previous utterance, and he provides inadequate information with respect to quality and quantity. However, the response of the next utterance shows how the $\mathrm{H}$ resorts to conversational implicatures to get the intentional meaning with regard to context. Second, can we consider "we are Arabs" as a request based on speech acts theory? My answer is "yes". Almost all approaches and theories to discourse analysis urge that utterances cannot be evaluated in isolation of context and the sequences of speech. If we consider the sequence, we will obviously discover that example (1-f) is a response to a previous request. $S$ in (1-f) translates the word, the question is why?

If example (1-e) was not referring to a request through which the speaker wanted the hearer to translate the word, the speaker of (1-f) wouldn't do so. By saying "we are Arabs" the speaker wants to reveal a situated meaning in which he would say for example "would you mind translating the word "compulsory?". According to Austin's theory, the performative in this example carries indirect force, and the $\mathrm{H}$ resorts to infer such implicit effect which is labeled "indirect speech act", Levinson (1983:264). We argue that although the utterance has no linguistic feature of a request "the structure is a declarative mode", the hearer could infer the conversational meaning. Thus, we cannot deal with one theory or approach in isolation; for instance, in this example we may start with "speech acts theory" at the surface level of analysis. Then it is inevitable to use Grice's theory to implicatures to describe for example the speaker in "we are Arabs" could infer the intentional meaning of "excuse me". On the other hand, using Grice's theory to evaluate "interpretation" and "intention" per se is insufficient without considering the role of context; variables suggested by the "interactional sociolinguistic approach". Therefore, the integrative approach suggested by Hajji-Hassan (2010) is no doubt a very effective approach to discourse analysis.

In sum, the utterance "we are Arabs" is an attempt to set micro identity in that the two males have the same background knowledge, and this knowledge is a part of their educational level. Micro identity includes characteristics of similarities and differences among the parties who are participants of the current talk. Similarities are set between the two males with respect to cultural and educational background which in turn in variance with the third participant. Moreover, such educational level is part of their cultural identity that reflects the broader level. The broader level is "macro identity" which refers to Arab people who live in this society and they are members of the same society. We can also argue that the deictic expression "we" refers to all parties because it is in its symbolic use; by monitoring the speech even, $\mathrm{S}$ of (1-e) does not use gestures to refer to (himself and Mohamad); therefore, it can be an evidence to the exclusion of distance between the parties in regard to nationalism. The speaker likely wants to generalize his idea that all of them including his mother belong to the same society that speaks the same language, if this is true, then the speech act carries a sort of positive politeness. I may posit that the positive politeness has an evidence at this point in the sense that the speaker instead of being rude to his mother which is morally unacceptable like for example saying "don' $t$ use English, we all are Arabs" that carries a function of order in an imperative form, he resorts to figurative language to convey his message. Taking another perspective of politeness theory, it can be claimed that the speaker could follow the principles stated by Robin Lakoff and illustrated by (Holmes, 2008). These principles are

1- Don't impose: e.g., using models or hedges "I am afraid that we don't understand the word, would you mind translating the word?"

2- Give options: e.g. "I guess compulsory means...." " I don't think that I have heard this word before, it would be nice to explain it"

3- Be friendly: e.g., using informal cues "Dear mother, we would like to know the word".

Based on the above assumption, one could claim that saying "we are Arabs" may carry a threat in its apparent surface or a strong cue in which S likely wants to impose force that it was unacceptable to use English. However, the speaker was not rude to the extent of being threatening; of course, such judgment is a biased perspective to scientific analysis, but not to personal beliefs.

According to gender perspective, it could not be claimed that the speaker takes the role to talk to support his cousin because of gender similarity. In other words, is this issue related only to males? To my best knowledge this issue "someone is incompetent in one language" can be a matter to both males and females. So, I have no evidence for approval or disapproval.

3-Speaking for another and taking the role of the other

When one talks, he potentially selects another one to take the role and move on or resuming his talk. Speaking for another can be used in a deeper way to interpret one particular utterance in different ways. Put in another way, speaking for another is achieved by two ways: taking the role of one's self or taking the role of another who is sharing the speech event by monitoring the sequential coherence. Schiffrin (1994) suggests that the situational event does not constitute speakers' utterances per se; rather, the participants are resources of the construction of particular language structures that suit that situation. Put in another way, the interactional situation imposes the parties to select what makes their communication consistent with the situated meaning, but these parties don't respond blindly; they have their choices to construct the situation and make it useful for particular interactional function. To illustrate the idea in a more explicit way, example 2 reflects how one utterance, even if it is created, is a result to a prior recourse and it can be another 
resource to sequential and different utterances that carry different interpretations. It is said that each utterance is stemmed from a previous one and stemming is both context bound and text bound, and in turn it provides an area for another stream to originate and take part; we may express it as "each utterance is an effect to a prior one and it is a prior cause to a coming one".

Example (2)

In this example the speaker narrates what happened at work

a. Guys: There is a lecture?

b. Adnan: Yes, No, no I am a technician.

c. Guys: Ok, come on in and have coffee.

d. Adnan: No, no thank you.

Let's discuss how sequential coherence provides different context interpretation. We will draw on "take the role of the other" as a strategy to explore the potential sequences stemmed from one utterance. As mentioned above each utterance is considered as a resource from which a slot is available to the other utterance; the void is to be filled with a response. Back to our example, utterance (2-c) is speech act in which an offer of having coffee is done by the speakers. At a level of perlocutionary act, the force of (2-c) is activated on (2-d) in which the hearer responses to their offer by saying "No, thank you". Here, the exchange of utterance reflects the sequential coherence. Put another way, (2-c) is a source from which a slot is built for (2-d) to take part, in turn (2-d) itself is a prior base from which another slot is to be built for the next utterance. What important is that how to build different interpretations based on one resource with reference to contextual understanding. We will consider example (2-d) to show how it can be a resource "basis" for 1context representation and 2- different responses. The offer prepares for effect which is the existence of the response "refusal", and the refusal prepares for other effects understood within context, these effects can be for example:

1- Why? You don't like coffee?

2- You are busy?

3- Potentially you don't drink coffee before breakfast.

4- Turkish?

5- We always welcome new friends.

6- It would be our pleasure if you join us.

7- We've just arrived, coffee is still hot.

8- Have some rest.

The above examples are only some potential responses to speaker's rejection. These potentials stand for two notions of "speak for another" these are "self" and "other". Let us start with "self"; it means that the participant makes a package of responses based on what he understands form his point of view that is "self" reflection. On the one hand, examples (5-8) reveal that the speakers resort to "themselves" as a resource from which they can posit further and different responses; however, the context is still in activation. On the other hand, examples (1-4) the speakers take the role of the "other" as a base from which they suggest the potential responses. In other words, the speaker(s) takes the role of the animator who is not basically the resource of the talk but the one who transfer the talk. Noted here is that in examples from 1 to 4 "you" is used, for instance, in "you are busy" means as if the speaker wants to say "I can't join you because I am busy", although he does not say that, but the others say it on his behalf; in other words, they infer one potential intention. In the same vein, in example "Turkish?" they assume that the hearer may prefer Turkish coffee, so it is the base of his refusal. In this regard, the researcher may posit a critical point to what Schiffrin (1994) suggests in her discussion " Interactional sociolinguistics tries to avoid imputing intentions to speakers.... this approach thus uses to account for why someone says or does something is not the construct of "motivation" but "discourse strategy"" (p. 132). If so, how can we analyze "speaking for another" in the sense of "other" without the involvement of participant's "intention"?

Return to our analysis, examples 5-8 give indications of how one frame within context can be a base to different responses. For example, the refusal of the offer makes the inviters think of other ways to impose upon their offer by saying "It would be our pleasure if you join us" that is another way to convince him of having coffee, "coffee is still hot" carries the same perspective. On the other hand, "we always welcome new friends" is an attempt to minimize distance and strangeness. If the last explanation is true, the inviters assume that the hearer feels he has less familiarity and so he is hesitant to accept the invitation; however, these different interpretations of the refusal are based on context and inferencing speaker's intention. Thus, it causes deficit in analysis when we attempt to deal with speaker's intention in isolation from discourse strategies.

4- Two types of "wants" and "face threatening"

Under this section, we will shed light on how discourse can be analyzed from two perspectives that are "wants" and "face threatening". To base for such analysis, we will draw on the principles of speech acts theory; especially acts of commissives that include offers (Schiffrin, 1994). Theoretically, offer requires that S does A for H; this means that the act is to be done for the benefit of $\mathrm{H}$. Thus, there are stages to be considered: $1-\mathrm{S}$ does not know if $\mathrm{H}$ wants $\mathrm{A}, 2-\mathrm{S}$ is to find out if $\mathrm{H}$ wants $\mathrm{A}, 3$ - when $\mathrm{S}$ knows that $\mathrm{H}$ wants $\mathrm{A}, 4-\mathrm{S}$ commits to do A. Thereupon, two types of "wants" are suggested: 
1- $\mathrm{H}$ wants $\mathrm{A}$, but $\mathrm{S}$ is uncertain what $\mathrm{A}$ that $\mathrm{H}$ wants, so $\mathrm{S}$ should resort to guessing to know the $\mathrm{A}$ that $\mathrm{H}$ wants. The problem with this type is that guessing may cause a threat to $\mathrm{H}$ because he may be conservative to his needs and wants in the sense that he does not want $S$ to interrupt his own desires. So, hearer's negative face like "rejection" is threatened by the S's offer. In other words, hearer's negative face is an attempt to hide internal state, so when guessing is made it may uncover that internal state; that is why it is considered as a threat to H's negative face. Instance is that: I as (S) try to uncover your want as $(\mathrm{H})$ although you try to hide it through negation "negative face".

2- $\mathrm{S}$ wants to do something for $\mathrm{H}$. The problem here is when $\mathrm{H}$ rejects the offer. Rejection means that $\mathrm{H}$ does not want what $\mathrm{S}$ wants. In this case a threat is directed to S's desire. In other words, by offering something S wants to do A to $\mathrm{H}$ but H's refusal is considered as a threat to his desire "S's desire" in the sense that his want and H's want are not alike. That is why it is described as a threat to "positive face". Positive here refers to S's desire to do A to $\mathrm{H}$, so when this offer is met by H's rejection it may cause a threat to his desire.

In sum, when $\mathrm{H}$ rejects $\mathrm{S}$ 's offer this means that $1-\mathrm{S}$ fails to guess what $\mathrm{H}$ wants, and 2- $\mathrm{S}$ 's want and H's want are different. Hence, and based on offer refusal, threats are classified into two categories, self and self-other relationship. Threat to self means "you as $\mathrm{H}$ does not want what I want as S". Threat to self-other relationship means "I as S fail to make the right guess about your want as $\mathrm{H}$ because there is not enough familiarity between us". The previous lines of thoughts may give us background knowledge of why $\mathrm{H}$ sometimes refuses $\mathrm{S}$ 's offer.

Trying to apply what is just posited, we could claim that the refusal of the offer in examples:

a. Guys: $\underline{\mathrm{Ok} \text {, come on in and have coffee. }}$

b. Adnan: No, no thank you.

reveals that what $\mathrm{S}$ wants does not meet H's want. So, we assume that this want "offer" in "Ok, come on in and have coffee" is S's desire. The rejection indicates that the guessing the Ss draw on fails to interrupt the internal state of the H; that is what the latter wants. In other words, Adnan's refusal to have coffee with them is evidence that the speakers wanted to do an action for the hearer "they thought it was for H's benefit", yet they could not uncover the H's real want. We can safely say that the refusal of that type of "want" is a threat to S's positive face, to the desire of the speakers. Thus, since the offer is met by rejection "the hearer does not want what the speakers want to do for him" it is self-threat. Can we assume it is also a threat to self-relationship? I suggest "yes" we can. My justification to that is the unfamiliar relationship between the speakers and the hearer. He met them by accident, and they do not know each other. On such bases, it would be very evidence that the speakers are unable to guess hearer's favorites, habits, and personal needs and wants. This can be known by returning to the context; the story that was told by Adnan about those students. Consistent with the goal of analyzing types of wants mentioned above that they give us background knowledge of why $\mathrm{H}$ sometimes refuses S's offer; can we justify Adnan's refusal in this context? Potentials are posited as follows

1- He does not like coffee

2- He does not drink coffee at that time

3- He has had enough before meeting them

4- He lacks familiar relationship with them

5- He is busy

In fact, neither of the above can be proved because the context lacks the sequential arrangements. In other words, no related utterances follow the utterance of refusal to evaluate which of the above potentials suits the offer refusal; lack of perlocutionary act.

\section{SUMMARY}

A- There can be no doubt that no single approach per se is comprehensive by its own to discourse analysis.

B- The integrative approach used in this paper can be thought of a highly effective tool to discourse analysis in the sense that it considerably strikes two sub-integrative levels: socio-linguistic context stemmed from ISA and pragmatic context stemmed from Conversational Implicatures. However, what applies to all approaches as mentioned in (A) above, also applies to the integrative approach.

C- Interactional sociolinguistic approach provides a highly effective repertoire to discourse analysis. Principles of ISA open the doors through which one could investigate how people communicate in two levels, macro- and micro-interaction (Gumperz, 2012). It also enables analysts to explore how people use their background knowledge "presuppositions" and translate them in contextualization cues to activate their intentions, needs, and feeling. On the other hand, Grice's theory to pragmatics presents a pool of tools analyst can use to overlap between two critical processes in any discourse that are speaker's intentional meaning and hearer's interpretation (Yule, 1996), (Cruse, 2010) and (Horn \& Ward, 2006).

D- Both approaches crystallize variables and dimensions surrounding any interactional event to present potential understandings of participants' messages. It is an attempt to read the performance that we can see based on thoughts and intentions which we cannot see.

E- Analyzing data of discourse can never be delineated; in other words, the analyst should go backwards and forwards to cover all potential interpretations of discourse. Using background knowledge and socio-cultural information of the participants is the key to interpret discourse in its social aspect "contextualization cues". On 
the other hand, contextualization cues are the gate through which one can enlighten the social context to which participants belong.

F- Speaking for another assumed by ISA proves its potential to serve as a discourse strategy. It can be a key to understand communicative goals behind some interactional processes such as: turn-taking, taking the role of another, parameters of responsibilities. In addition, speaking for another changes in regard to structure of the conversation, participation framework, and setting of the conversation.

G- Outcomes posit two important issues to ISA; macro-interactional level of Goffman's and micro-interactional level of Gumperz's. The latter focuses on the social interaction of discourse in a specific event of communication, whereas the former focuses on a broader concept that is the social organization of the society. The relationship between the two levels which is critical to interactional discourse and critical to discourse interpretation is posited by Goffman.

H- The results of the current research can be used for further investigations on i.e. why speakers use certain speaking strategies? On the other hand, the results can give an opportunity to criticize the principles of ISA from two perspectives that are weaknesses and strengths. Although the samples used in this paper are limited; however, it can be a good start for researchers to duplicate the research methodology to explore more insights of ISA specially in corpus pragmatics.

\section{REFERENCES}

[1] Altieri, Ch. (1981). Act \& QuAdnanty: A Theory of Literary Meaning and Humanistic Understanding. Amherst, MA.: University of Massachusetts Press.

[2] Auer, P. \& Luzio, D. A. (1992). The Contextualization of Language. Philadelphia: John Benjamins B. V.

[3] Birner, B. J. (2013). Introduction to Pragmatics. San Francisco: Wiley-Blackwell.

[4] Cruse, A. (2011). Meaning in Language: An Introduction to Semantics and Pragmatics (3rd ed). Oxford: Oxford University Press.

[5] Cutting, J. (2002). Pragmatics and Discourse. London: Routledge.

[6] Eerdmans S., Prevignano, C. \& Thibault, P. (2003). Language and Interaction. Discussion with John J. Gumperz. Philadelphia: John Benjamins Publishing Company.

[7] Fairclough, N. (2003). Analysing Discourse: Textual Analysis for Social Research. London: Routledge.

[8] Gumperz, J. (2012). Interactional Sociolinguistics: Perspectives on Intercultural Communication. The Handbook of Intercultural Discourse and Communication. Wiley Online Library.

[9] Haji-Hassan, I. A. (2010). Sociolinguistics and Interactional Discourse: Theory and Practice. Final Report, Project No. 3/1/41334. Riyadh: Research Center of Faculty of Arts, King Saud University.

[10] Holmes, J. (2008). An Introduction to Sociolinguistics. UK: Pearson Education Limited.

[11] Horn, L. \& Ward, G. (2006). The Handbook of Pragmatics. Malden: Blackwell Publishing Limited.

[12] Johnstone, B. (2002). Discourse Analysis. UK: Blackwell Publishing Ltd.

[13] Jorgensen, M. \& Philips, L. (2002). Discourse Analysis as Theory and Method. London: SAGE publications Ltd.

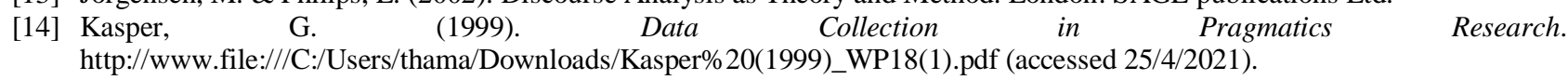

[15] Levinson, S. (1983). Pragmatics. UK: Cambridge University Press.

[16] Schiffrin, D. (1994). Approaches to Discourse. UK: Blackwell Publishers.

[17] Thomas, J. (2013). Meaning in Interaction: An Introduction to pragmatics. New York: Routledge.

[18] Yule, G. (1996). Pragmatics. Oxford: Oxford University Press.

Thanaa Abdulrazzaq Alhabuobi is Saudi and living in Saudi Arabia; Almadunah Almunawarrah. She is an Assistant Professor and working as a staff member at Languages and Translation Department / Faculty of Arts and Humanities / Taibah University. The email address is thamar_5@hotmail.com. 